\title{
Mutation in a putative glycosyltransferase- like gene causes programmed cell death and early leaf senescence in rice
}

\author{
Shanwen Ke ${ }^{1 \dagger}$, Shuchun Liu ${ }^{1 \dagger}$, Xin Luan ${ }^{1}$, Xin-Ming Xie ${ }^{1}$, Tzung-Fu Hsieh ${ }^{2,3}$ and Xiang-Qian Zhang ${ }^{1 *}$ (D)
}

\begin{abstract}
Leaf senescence is a genetically regulated, highly complex and ordered process. Although it has been extensively studied, the mechanism of leaf senescence is not well understood. In this study, we isolated a rice mutant, designated as premature senescence leaf ( $p s)$, which exhibits early senescence and spontaneous lesion mimic phenotype after flowering. The ps/ mutant displays programmed cell death with elevated accumulation of reactive oxygen species (ROS). Molecular and genetic analyses revealed that the phenotypes were caused by a phenylalanine deletion in the OSPSL (LOC_Os12g42420) that encode a putative core 2/I branching beta-1,6-Nacetylglucosaminyl transferase predicted to be involved in protein glycosylation modification. OsPSL mRNA levels increased as senescence progressed, with maximum accumulation of transcripts at late senescence stages in WT plants. Moreover, remarkedly down-regulated transcriptional levels of O-linked N-acetylglucosamine (O-GIcNAc) transferases (OGTs) genes were observed in ps/ mutant, supporting the occurrence of impaired O-glycosylation modification. Proteomic analysis showed that ethylene-related metabolic enzymes including S-adenosyl methionine (SAM) synthetase (SAMS) were significantly upregulated in the ps/ mutant compared with WT. Consistent with the proteomic results, ethylene concentration is higher in ps/ mutant than in wild-type plants, and transcript levels of ethylene synthesis and signal transduction genes were induced in ps/ mutant. The early leaf senescence of ps/ can be partially rescued by ethylene biosynthesis inhibitor aminoethoxyvinylglycine treatment. These results highlight the importance of protein O-glycosylation in PCD and leaf senescence, and suggest a possible role of OsPSL in ethylene signaling.
\end{abstract}

Keywords: Rice, PCD, Glycosylation, Senescence, Ethylene

\section{Background}

Leaf senescence is a highly complex and programmed process and involves a series of cytological and biochemical changes. The onset of leaf senescence depends on developmental programs and environmental signals; i.e., it occurs in an age-dependent manner. Consequently, young leaves are insensitive to senescence-inducing signals (Jibran et al., 2013). In annual plants, flowering is associated with senescence and death of the whole plant. During senescence, photosynthetic pigments such as chlorophyll and carotenoids are degraded and thus

\footnotetext{
*Correspondence: aacrav@163.com

†Shanwen Ke and Shuchun Liu contributed equally to this work

'Guangdong Engineering Research Center of Grassland Science, College of Forestry and Landscape Architecture, South China Agricultural University, Guangzhou 510642, China

Full list of author information is available at the end of the article
}

yellowing of leaves is a morphological indicator of senescence (Thakur et al., 2016). On the other hand, leaf senescence can also be accelerated due to various environmental stresses including pathogen attack. In plants, one of the most common defense responses to pathogen attack is the hypersensitive response (HR). It has been shown that HR results from programmed cell death (PCD) process, as evidenced by the existence of mutants that spontaneously activate the HR in the absence of a pathogen (Dangl et al., 1996). The lesion mimic mutants (LMM) exhibiting HR lesions in the absence of pathogens are thought to be defective in genes that control PCD, representing a powerful tool for the study of PCD in plants. Besides induced by pathogen, PCD is also essential for growth and development in animals and plants, including leaf senescence (Trobacher, 2009). 
However, the molecular mechanisms of PCD and leaf senescence are still not well understood in plants.

More than $50 \%$ of the proteins in eukaryotes are glycoproteins (Gomord et al., 2010). Protein glycosylation can be classified into two main categories: $N$-linked glycosylation at the amide group of asparagine (Asn) residues and $O$-linked glycosylation at the hydroxyl group of serine (Ser), threonine (Thr), hydroxylysine or hydroxyproline (Hyp) residues in the protein chain (Gomord et al., 2010). There are multiple types of protein $\mathrm{O}$-glycosylation. Mucin-type O-glycans is the most abundant O-glycans in humans. Mucin-type O-glycosylations can be further classified into eight major groups (core1-core8) (Moran et al., 2011; Ye et al., 2015). In general, O-linked glycans contain 1-20 carbohydrate residues, which are shorter than N-linked glycan chains. For core1-core4 mucin-type O-glycans, the carbohydrate chain is initiated with an $\mathrm{N}$-acetylgalactosamine (GalNAc) residue linked to Ser or Thr. For example, core2 mucin-type of O-glycosylation starts with the addition of a GalNAc residue onto the hydroxyl groups of Ser or Thr. Core $2 \beta-1,6-\mathrm{N}$-acetylglucosaminyltransferase-1 (C2GNT) catalyzes the transfer of $\mathrm{N}$-acetylglucosamine from uridine diphosphate- $\mathrm{N}$-acetylglucosamine with a $\beta 1,6$-linkage to $\alpha$-N-acetylgalactosamine of a core $1 \mathrm{O}$-glycan (Kojima et al., 2015). For core5-core8 mucin-type O-glycans, contain one residue. For example, $O$-GlcNAcylated proteins consist of a single $O$-linked $\mathrm{N}$-acetylglucosamine on serine and threonine residues belong to core8 mucin-type glycosylated protein (Xu et al., 2017).

Several studies in Arabidopsis have uncovered functions for O-glycosylation in multiple important biological processes during plant development including flowering and epigenetic modification (Zentella et al., 2016; Xu et al., 2017; Zentella et al., 2017; Xing et al., 2018). In this paper, we characterized an early senescence rice mutant psl with HR-like lesions in the absence of pathogen attacks. Using a map-based cloning approach, we determined that OsPSL encodes a putative member of the core $2 / \mathrm{I}$ branching beta-1,6-N-acetylglucosaminyl transferases family, which is involved in protein $\mathrm{O}$-glycosylation modification. Our study provides an important evidence for a key role of a putative acetylglucosaminyltransferase in regulating leaf senescence in rice.

\section{Methods}

\section{Plant materials}

A spontaneously occurring rice early senescence mutant psl was isolated from the Oryza sativa L. ssp. Japonica cultivar Zhonghua 11.

\section{Histochemical staining and quantification of ROS}

Histochemical staining was performed on fresh leaves as previously described (Qiao et al., 2009) with modifications.
In brief, fresh leaf examples were vacuum infiltrated in $0.5 \mathrm{mg} \mathrm{ml}^{-1}$ nitro blue tetrazolium (NBT) or $1 \mathrm{mg} \mathrm{ml}^{-1}$ 3,3'-diaminobenzidine (DAB) for $10 \mathrm{~min}$, and then left at room temperature for $12 \mathrm{~h}$ in the dark. After staining, the chlorophyll was extracted by soaking the samples in $90 \%$ ethanol for $3 \mathrm{~h}$ at $42^{\circ} \mathrm{C}$ or until the green pigment was completely removed. $\mathrm{H}_{2} \mathrm{O}_{2}$ and $\mathrm{O}_{2}{ }^{-}$levels in the flag leaves two days after flowering were quantified according to Yang et al. (Yang et al., 2016).

\section{DNA laddering}

Flag leaves from wild-type and psl plants were collected at three different stages: 10 days before flowering, and 2 or 7 days after flowering. The DNA extraction was conducted using a convenient method as previously described (Zhang et al., 2013) with modifications. In brief, a small piece of leaf tissue ground to a fine powder (approximately $100 \mathrm{mg}$ ) was incubated with $1000 \mu \mathrm{L}$ of buffer at $75^{\circ} \mathrm{C}$ for $30 \mathrm{~min}$. Following centrifugation at $12,000 \mathrm{rpm}$ for $10 \mathrm{~min}, 500 \mu \mathrm{L}$ of the supernatant was transferred to fresh tubes and the DNA was precipitated with $500 \mu \mathrm{L}$ of islpropanol with $50 \mu \mathrm{L}$ sodium acetate buffer ( $\mathrm{pH}$ 5.2). For the DNA fragmentation assay, $\sim 10 \mu \mathrm{g}$ of genomic DNA was separated by electrophoresis on a $1.5 \%$ agarose. Extraction buffer: 100 $\mathrm{mM}$ Tris- $\mathrm{HCl}$ at $\mathrm{pH} 8.0,10 \mathrm{mM}$ EDTA at $\mathrm{pH} 8.0,1 \mathrm{M}$ $\mathrm{KCl}$.

\section{Map-based cloning}

For map-based cloning of the OsPSL gene, 692 individual plants showing early leaf senescence were selected from an $\mathrm{F}_{2}$ population derived from a cross between the psl mutant and indica var. Huajingxian74. Bulk segregant analysis (BSA) was first performed for preliminary genetic mapping (Michelmore et al., 1991). For BSA, two DNA bulks were constructed by mixing an equal amount genomic DNA from 20 wild-type and mutant plants from the $F_{2}$ mapping population, respectively. Simple sequence repeats (SSRs) were identified using SSRHunter software (Li and Wan, 2005). For fine mapping, insertion-deletion (InDel) markers were obtained according to the rice DNA polymorphic database between Nipponbare (O. sativa ssp. japonica) and 93-11 (O. sativa ssp. indica) (Shen et al., 2004). Genomic DNA was extracted from young leaves of each parent and $F_{2}$ individuals using a convenient method (Zhang et al., 2013). The OsPSL gene was selected from an approximately $47.8-\mathrm{kb}$ region as the candidate gene. To find out the mutation site, we amplified the corresponding fragments from the psl mutant and wild-type plants, respectively. Primers used for the map-based cloning were listed in Additional file 1: Table S1. 


\section{Vector constructs and rice transformation}

For complementation of the $p s l$ mutation, the full-length coding sequence of OSPSL was amplified using the following primers: PLSF (GGTACCTCTAGAATGGCGC TGCCGCACGCCGCCT) and PLSR (ACTAGTCTA CCATGGGTCTCGCAGGATGACGGA). The 1098-bp PCR product was cloned into pCUbi1390 binary vector. The resulting plasmid was introduced into the calli generated from the mature seed embryos of the psl mutants through the Agrobacterium tumefaciens (strain EHA105)mediated method (Hiei et al., 1994).

\section{Gene expression analysis}

Total RNA was extracted from frozen samples using TRIzol reagent (Invitrogen) according to the manufacturer's instructions. After RNase-free DNase treatment, and first strand cDNA was generated using a Revert Aid First Strand cDNA Synthesis Kit (Thermo Scientific). Quantitative RT-PCR (qRT-PCR) was performed using a SYBR Premix Ex Taq ${ }^{\mathrm{Tm}}$ RT-PCR kit (Takara) following the manufacturer's instruction. The primers for qRT-PCR are shown in Additional file 1: Table S1. The rice 25sRNA gene was used as an internal control for all analysis. Three replicates were performed for each analysis, and average values and standard deviations are shown.

\section{Proteome analysis}

Identification of differentially expressed proteins was performed by Fitgene Biotech CO., Ltd. (Guangzhou, China) using two-dimensional gel electrophoresis (2-DGE) as previously described (Kim et al., 2008; Chen et al., 2013a) with some modifications. In brief, the samples of flag leaf two days before flowering were collected and total proteins were extracted from collected leaf samples of 10 plants with 3 bioreplicates. The 2-D gels were stained with Coomassie Blue G250 (Bio-Rad). Gels were scanned (300 dpi, 16-bit grayscale pixel depth, TIFF file) for image/data analysis performed using the Image Master 2D Platinum imaging software ver. 5.0. After quantitative detection, the significant differences of ( $>2$ folds, $p<0.05$ ) protein spots were marked and selected for further identification by MS if they were confirmed in three independent sample sets.

Mass spectra were acquired on a MALDI-TOF/TOF mass spectrometer, the Bruker-Daltonics AutoFlex speed $^{\mathrm{mm}}$ MALDI-TOF/TOF (Bruker, Germany). Peptide mass values were compared using the software flexAnalysis (Bruker Dalton). Protein database searching was performed with the MASCOT search engine against the NCBI nonredundant protein database (http:// www.ncbi.nlm.nih.gov/). The species selected was Oryza sativa.

\section{Quantification of ethylene and AVG treatment}

Leaf samples were collected $0,3,5,7$ and 10 days after flowering, and three leaves were placed into a $15 \mathrm{~mL}$ glass vial sealed with a gas-proof septum. After imbibition in a growth cabinet at $26^{\circ} \mathrm{C}$ for $30 \mathrm{~h}$, a $0.1 \mathrm{~mL}$ gas sample was withdrawn from the head space of each bottle using a gas-tight syringe (Hamilton), and the ethylene concentration was determination by gas chromatography (Shimaduz GZ-14CPF). The quantified data, divided by fresh weight and time, were converted to specific activities.

For phenotype analysis of the leaves in response to the exogenous ethylene inhibitor, wild-type and psl plants were sprayed 5 day before flowering with $50 \mu \mathrm{M}$ aminoethoxyvinylglycine (AVG), an inhibitor of ethylene biosynthesis, for 20 days (once per day) in a paddy field.

\section{Results}

Phenotypic characterization of rice ps/ mutant

A naturally occurring rice mutant with an early leaf senescence phenotype, named premature senescence leaf ( $p s l)$, was isolated from a japonica variety Zhonghua 11. Under paddy field conditions, the psl plants were almost indistinguishable from wild type (WT) plants before heading (Fig. 1a). After flowering, the psl mutant plants exhibited accelerated senescence compared with wild-type plants. Leaves displayed chlorosis at the early flowering stage, began to wilt at approximately 15 days after flowering, and eventually died at three weeks after flowering (Fig. 1a). Unlike the yellowing of leaves due to naturally senescence, small yellow lesions appeared on the leaves of psl mutant plants, whereas the leaves of wild-type plants at the same stage exhibited no such abnormal symptoms (Fig. 1b). In addition, the psl mutants had almost the same plant height and heading date but had obviously reduced seed setting rate and 1000-grain weight (Additional file 1: Table S2).

To determine the inheritance of $p s l$, we examined the phenotypes of progeny derived from a cross between psl and wild type (Zhonghua11). All $F_{1}$ plant displayed wild-type phenotype, and their $\mathrm{F}_{2}$ progenies showed a segregation ratio of 3:1 (normal: early leaf senescence $=$ 442:130; $\left.x^{2}=1.46<\chi^{2} 0.05=3.84\right)$, indicating that the mutant phenotype was controlled by a single recessive nuclear locus.

\section{Accumulation of reactive oxygen species (ROS) in pls}

To determine possible biochemical mechanisms involved in the early senescence and HR-like lesions in the psl mutant, we compared the ROS accumulation of flag leaves two days after flowering $\left(\mathrm{H}_{2} \mathrm{O}_{2}\right.$ and $\left.\mathrm{O}_{2}{ }^{-}\right)$between psl and wild-type plants by 3,3'-diaminobenzidine (DAB) and nitroblue tetrazolium (NBT) staining. As shown in Fig. 2, both $\mathrm{H}_{2} \mathrm{O}_{2}$ and $\mathrm{O}_{2}{ }^{-}$are significantly increased in psl leaves, suggesting that the accumulation of ROS may play an important role in triggering cell death in $p s l$. 

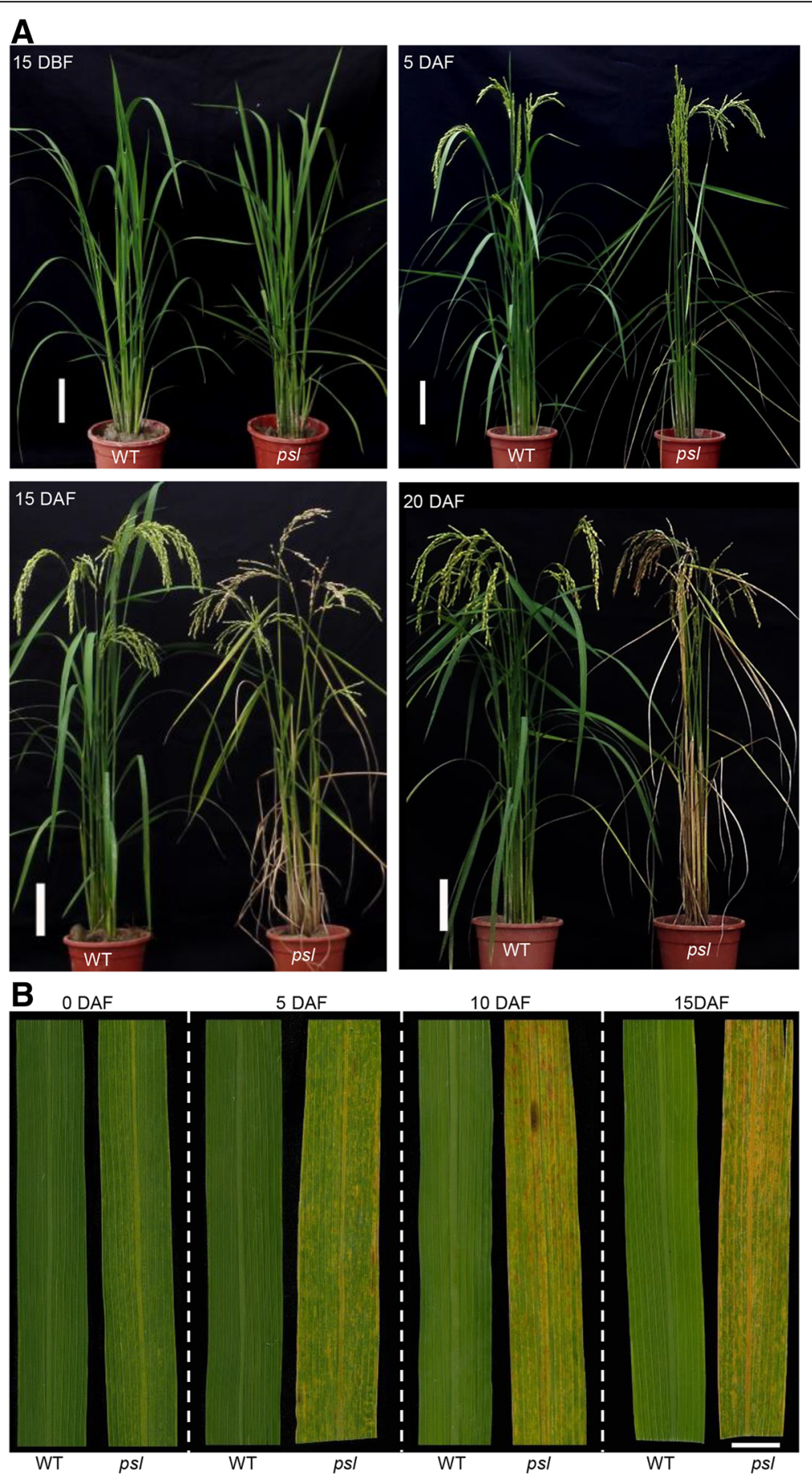

Fig. 1 Phenotype of the ps/ mutant. a Comparison of leaf phenotype in wild-type and ps/ mutant plants at different developmental stage. $\mathbf{b}$ Comparison of lesion mimic phenotype in wild-type leaves and ps/ mutant leaves. DBF: days before flowering; DAF: days after flowering. $\mathrm{Bar}=10 \mathrm{~cm}$ in $(\mathrm{A})$ and $1 \mathrm{~cm}$ in $(B)$

\section{DNA fragmentation analysis in mutant plants}

DNA fragmentation is a hallmark of PCD (Bröker et al., 2005). To determine whether the mutation of OsPSL cause PCD in psl mutant, we conducted the total DNA analysis of flag leaf of WT and psl plants at different stages ( 10 days before flowering, 2 and 7 days after flowering). DNA gel blot analysis showed an apparent DNA ladder in the total DNA isolated from psl plants after 

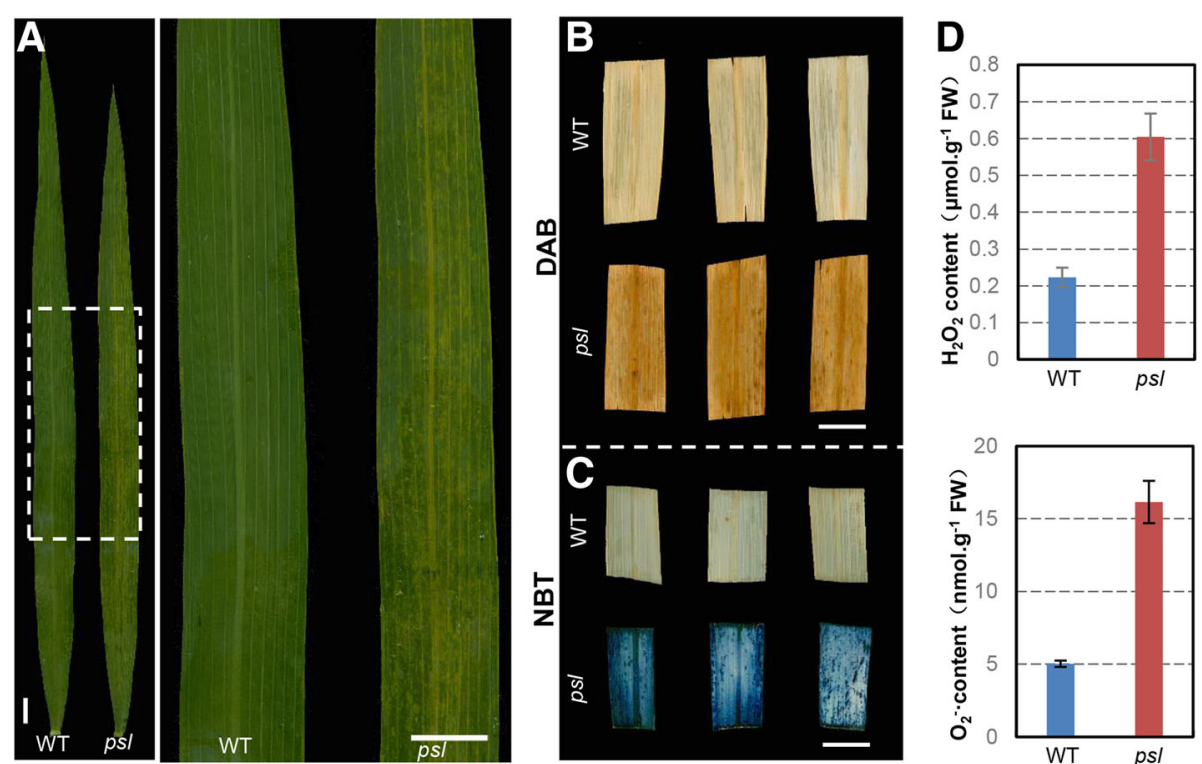

Fig. 2 Comparison of ROS levels between wild-type and ps/ plants. a phenotype of flag leaves two days after flowering. $\mathbf{b}$ Leaves stained with 3,3'-diaminobenzidine (DAB), showing the $\mathrm{H}_{2} \mathrm{O}_{2}$ levels in wild-type (WT) and ps/ plants. c Leaves stained with nitroblue tetrazolium (NBT), showing $\mathrm{O}_{2}^{-}$in WT and ps/ plants. d ROS $\left(\mathrm{H}_{2} \mathrm{O}_{2}\right.$ and $\left.\mathrm{O}_{2}{ }^{-}\right)$content in ps/ mutant. Scale bar, $1 \mathrm{~cm}$

flowering, whereas this pattern of DNA fragmentation was barely detectable in wild-type plants at an identical developmental stage (Fig. 3).

OsPSL encodes a putative acetylglucosaminyl transferases To identify the mutated gene responsible for the psl phenotypes, map-based cloning method was employed. Initially, BSA was conducted with 220 SSR markers distributing with $5-10 \mathrm{cM}$ intervals on 12 chromosomes. BSA revealed that OSPSL was located on the long arm of chromosome 12, and one SSR marker, PSM193, was closely linked to the OsPSL locus. Subsequently, linkage analysis was conducted by genotyping $870 \mathrm{~F}_{2}$ populations with several additional SSR markers located on chromosome 12, and the location of the OsPSL locus was identified inside two makers (RM235 and PSM192) on chromosome 12, with genetic distances of $1.2 \mathrm{cM}$ and $0.5 \mathrm{cM}$, respectively. For fine mapping of OsPSL, $>3000 \mathrm{~F}_{2}$ mapping populations consisting of 692 mutant individuals were developed from the cross between Huajingxian74 and the psl mutant. InDel markers were designed according to sequence differences between indica and japonica rice. Ultimately, the OSPSL locus was mapped to a $47.8 \mathrm{~kb}$ DNA region on chromosome 12 between InDel marker AL845347-13 and AL732532-7 (Fig. 4a). Within this 47.8-kb interval, there are eight predicted ORFs, including LOC_Os12g42420. DNA sequence comparison revealed a 3-bp deletion in the first exon of LOC_Os12g42420 in the psl and no sequence difference

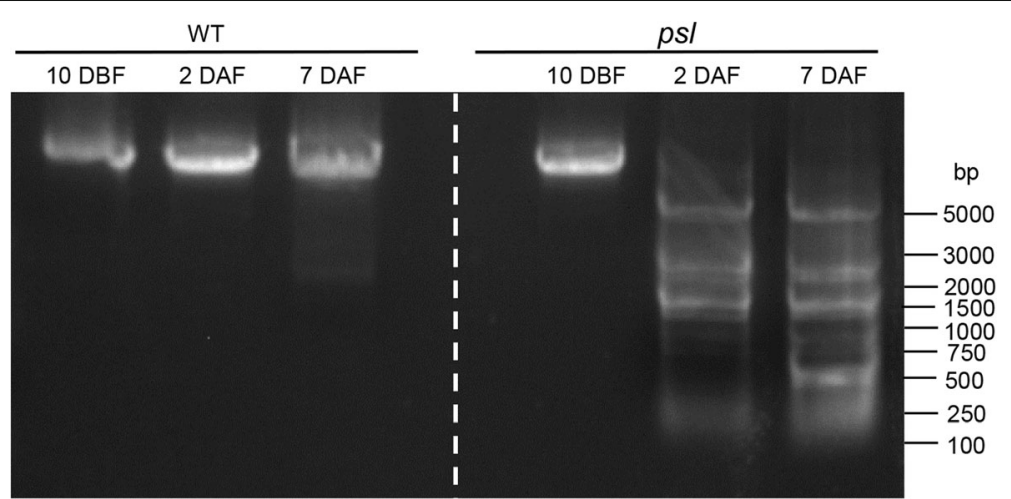

Fig. 3 DNA fragmentation in ps/ mutant. The DNA ladder of ps/ plants was detected by DNA gel blot analysis. Equal amounts of total DNA isolated from ps/ and wild-type plants at the same developmental stage were loaded in each lane. Positions of DNA standards (identified in bases) are indicated at right. 10 DBF: 10 days before flowering; 2, 7 DAF: 2 and 7 days after flowering 


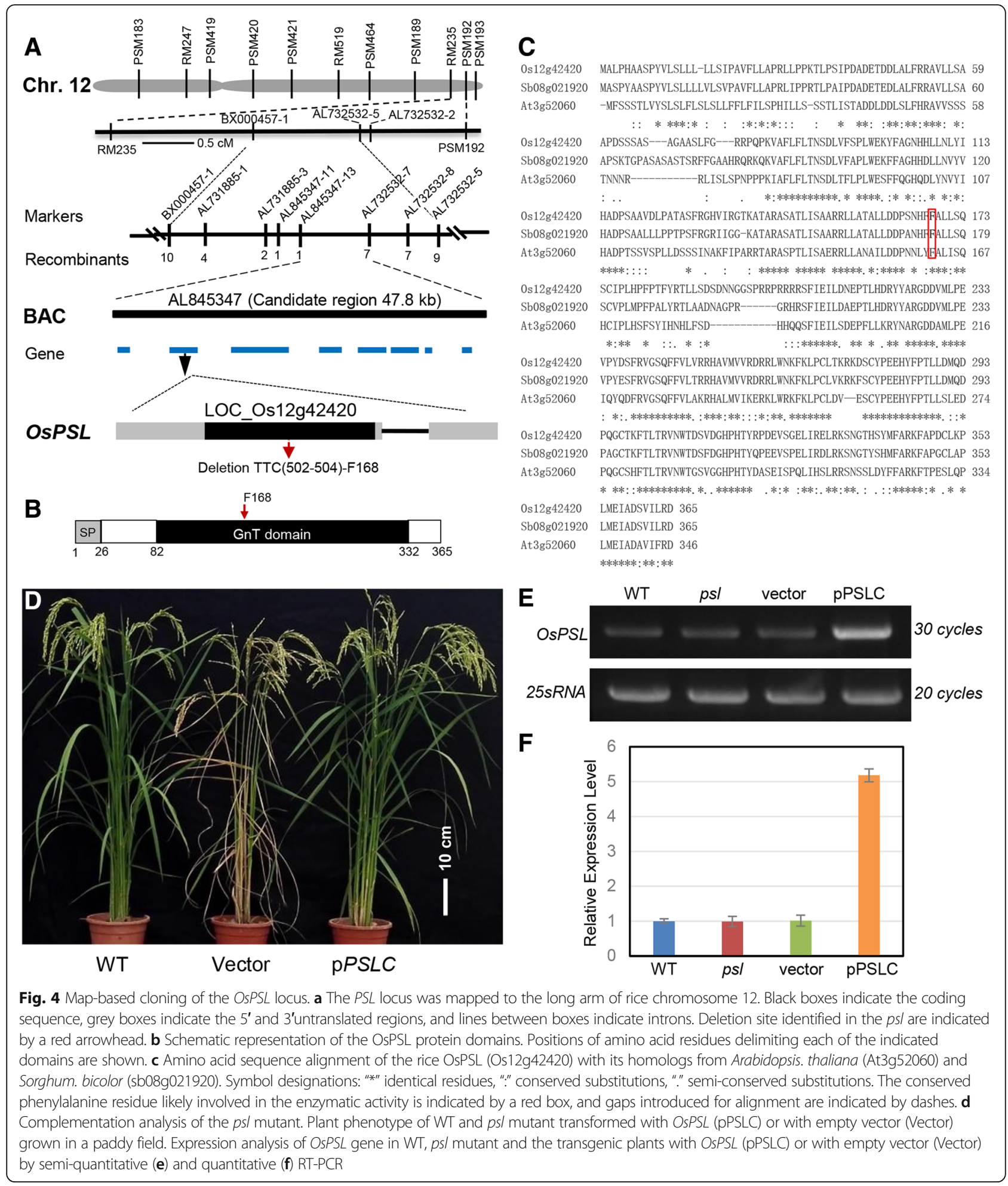

was found in the seven other genes (Additional file 1: Figure S1). LOC_Os12g42420 contains 1098 nucleotides of CDS and encodes predicted polypeptides of 365 amino acid residues with a calculated molecular mass of $41.03 \mathrm{kD}$. The 3-bp deletion in the psl mutant occurred at 502-504 bp downstream from the initiation codon ATG and is predicted to encode a phenylalanine (F168) residue (Fig. 4a).

Amino acid sequence analysis revealed that OsPSL (LOC_Os12g42420) belongs to the annotated family of core 2/I branching beta-1,6-N-acetylglucosaminyl 
transferases (Yang et al., 2017). OsPSL contains two functional domains, an amino-terminal signal peptide and a catalytic domain $(\mathrm{GnT})$ of a Branch family/glycosyltransferase family 14 (Fig. $4 \mathrm{~b}$ ). Further analysis demonstrated that OsPSL contains a conserved phenylalanine residue (F168 in OsPSL) potentially important for the enzymatic activity (Fig. 4c). Three-dimensional structure prediction by using Phyre2 server (http://www.sbg.bio.ic.ac.uk/phyre2) revealed that the F168 residue was located in a $\beta$-sheet and its deletion led to the absence of the $\beta$-sheet in OsPSL protein (Additional file 1: Figure S2).

To confirm the mutation in LOC_Os12g42420 was responsible for the abnormal phenotypes of psl mutants, we performed a genetic complementation test. An overexpression vector (pPSLC) containing the entire open reading frame (ORF) of OsPSL was constructed and introduced into psl mutants by A. tumefaciens-mediated transformation (Fig. 4d). The empty vector pCUbi1390 was also introduced to psl mutants as a control. We found that the psl mutant phenotype was rescued in 18 independent pPSLC transgenic plants with the overexpression of wild-type OsPSL compared to WT and psl mutant, while the empty vector failed to complement the psl mutant phenotype in 15 lines (Fig. $4 \mathrm{~d}-\mathrm{f}$ ). The findings confirmed that mutation in LOC_Os12g42420 is responsible for the mutant phenotype.

\section{Expression pattern of OsPSL}

Expression analysis showed that OsPSL was expressed constitutively across tissue types, but with preferential expression in seedling and leaf blade (Fig. 5a). Further we examined OsPSL expression in the leaves at different developmental stages. A kinetic analysis of OsPSL expression in flag leaves showed that, although the number of OSPSL transcripts increased gradually before heading, it increased dramatically just after flowering, while decreased rapidly in old leaf 30 days after flowering (Fig. $5 \mathrm{~b})$. Rice leaf matures from the tip to the base, displaying a developmental gradient, is an attractive model system for developmental studies. Consistent with this observation of different developmental stages, OsPSL expression increased gradually from the base to the tip of a fully expanded flag leaf two days before flowering, but decreased gradually from the tip to the base in the flag
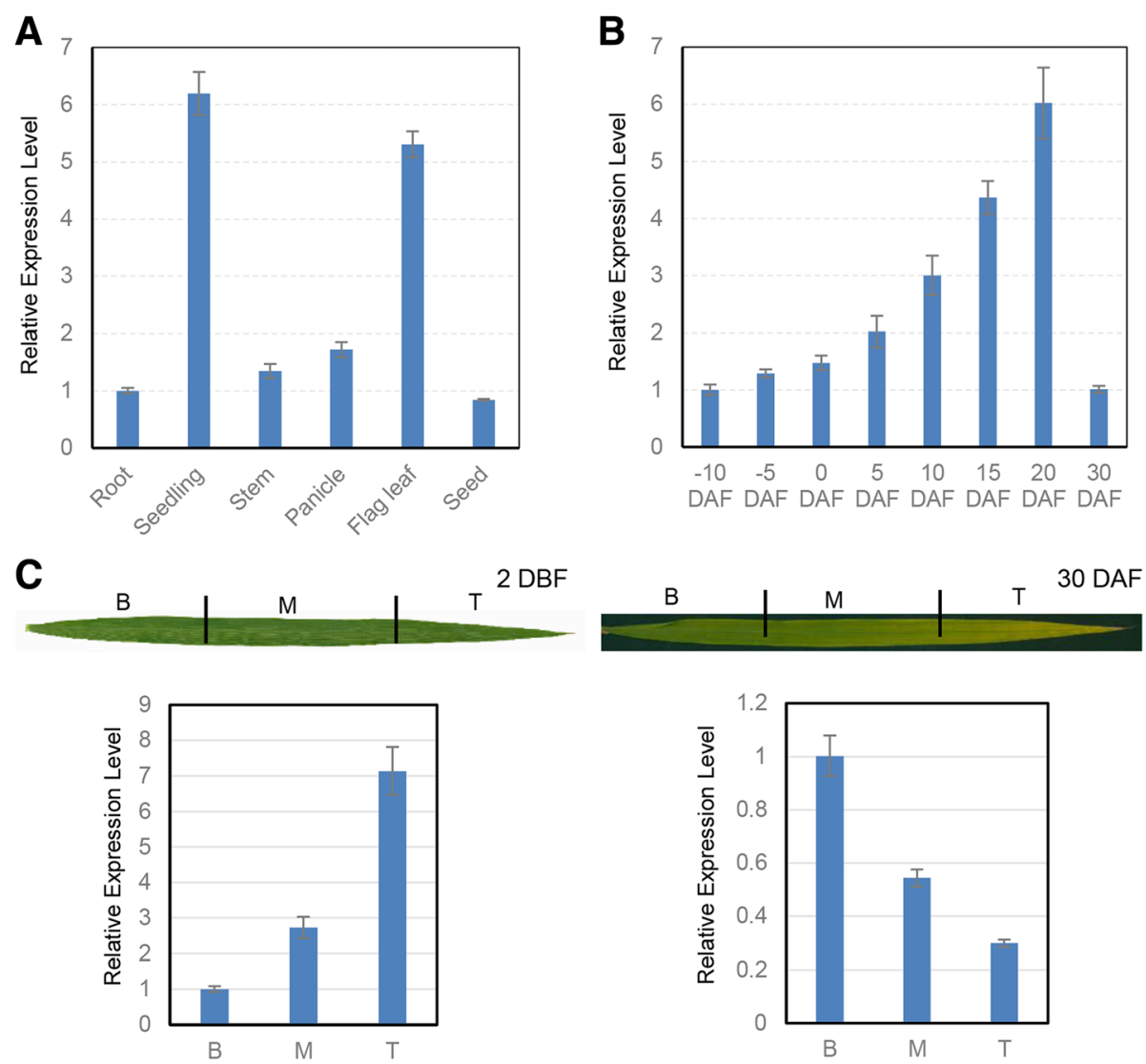

Fig. 5 Analysis of OsPSL expression. a Quantitative RT-PCR (qRT-PCR) analysis of OsPSL expression in various organs, including root and young seedling at the two-leaf stage, stem, panicle and flag leaf at booting stage, and seed 10 days after flowering (DAF). b Change over time in the OsPSL transcription levels of flag leaves. c OSPAL expression in different parts of the fully expanded flag leaf 2 days before flowering (DBF) and 30 DAF. B, base; M, middle; T, tip 
leaf 30 days after flowering, displaying yellowing of leave as result of the degradation of photosynthetic pigments (Fig. 5c). The results suggest that OsPSL plays an important role in delaying leaf senescence.

\section{Expression of O-glycosylation related-genes is altered in the $p s /$ mutant}

Mucin-type O-glycosylations are divided into eight major groups based on different carbohydrate residues (Moran et al., 2011; Ye et al., 2015) (Fig. 6a). Mucin-type core 8 $\mathrm{O}$-glycn is biosynthesized by $\mathrm{O}$-linked $\mathrm{N}$-acetylglucosamine (O-GlcNAc) transferase (OGT). O-linked $N$-acetylglucosamine (O-GlcNAc) modification affects diverse plant processes including response to hormones and environmental signals. Plants have two putative distinct O-GlcNAc transferases (OGTs), SEC- and SPY-like (Olszewski et al., 2010). Recently, it has been demonstrated that AtSEC acts as O-GlcNAc transferase whereas AtSPY is a protein O-fucosyltransferase in Arabidopsis (Zentella et al., 2016; Zentella et al., 2017). Rice has three putative OGTs genes, one SPY-like and two SEC-like genes (Shimada et al., 2006). To determine whether the mutation of OsPSL has an effect on the expression of rice OGTs, we conducted the transcript analysis of rice OGTs. As shown in Fig. 6b, three of rice OGTs genes, SPY, SEC1 and SEC2, were significantly downregulated compared to the wild-type plants. Given that the Arabidopsis DELLA protein RGA, a direct target of OGTs (Zentella et al., 2017), is a repressor in GA pathway, we examine the expression of rice $S L R$ and GID1 genes, encoding rice DELLA protein and GA receptor, respectively, in wild-type and psl plants. The abundances of the transcripts of $S L R$ and GID1 were also reduced in the $p s l$ mutant. The findings suggest that proteins glycosylation modification might be altered in psl mutant, consequently influencing GA signaling.

\section{Proteome analysis of the rice $p s l$}

To understand the molecular mechanisms of PSL mutation-induced cell death, we compared the protein profiles of psl mutant and WT by two-dimensional gel electrophoresis (2-DE) (Additional file 1: Figure S3) and found that 19 proteins were differentially accumulated (> 2-fold changes) between WT and psl mutant two days before flowering (Fig. 7). Among these 19 proteins, 17 were up-regulated and 2 were down-regulated, respectively, in psl mutant, which could be categorized into different functional classes (Table 1). Among them, some proteins including photosynthesis, metabolic enzymes,
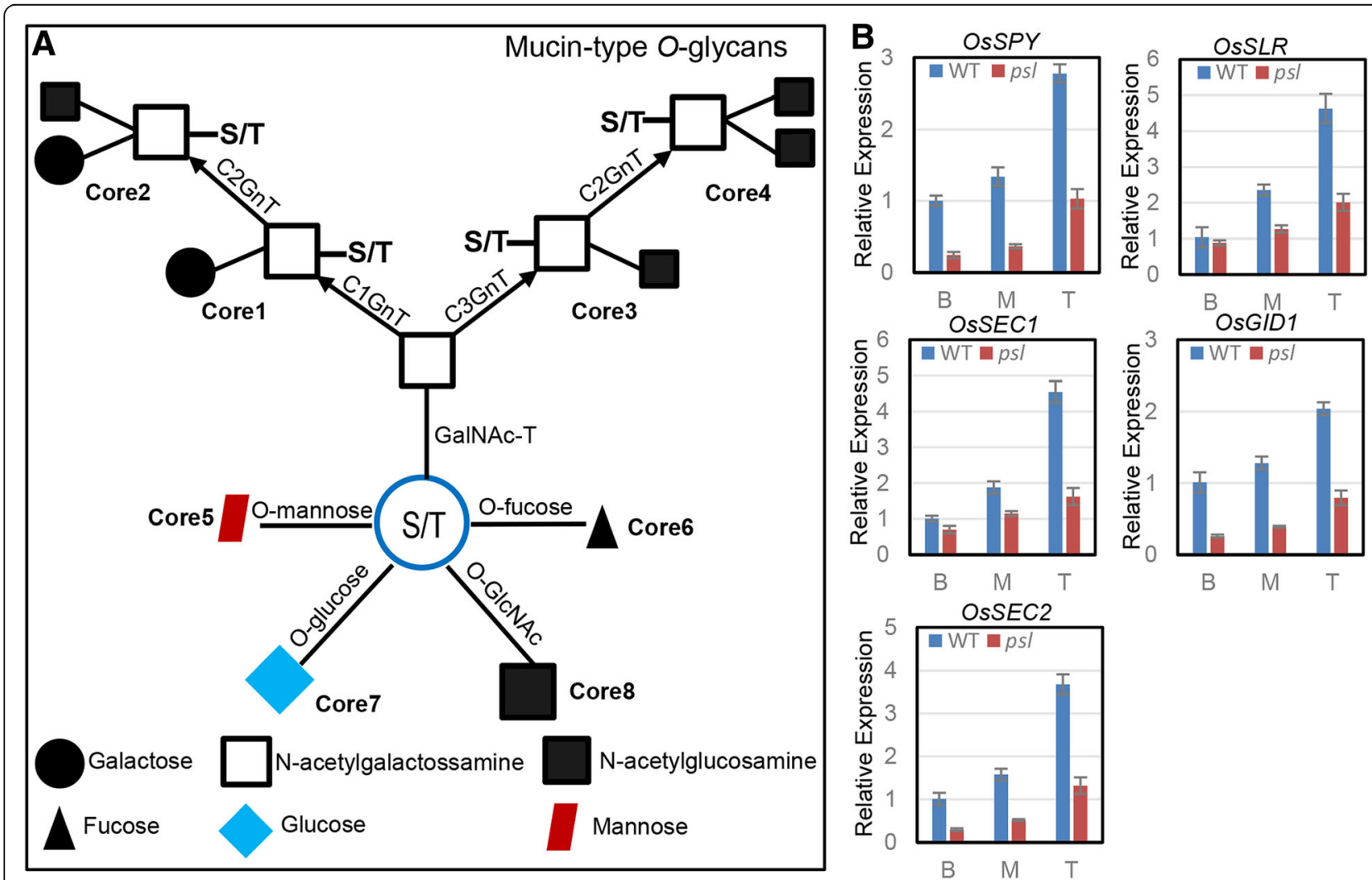

Fig. 6 Mutation of OSPSL has an effect on the expression of rice putative O-GlcNAc transferases (OGTs) genes. a Illustration of mucin-type Oglycan synthesis. $\mathbf{b}$ Expression analysis of O-linked glycosylation-related genes in different parts of the flag leaf in WT and ps/ mutant two days before flowering. B, base of leaf; $M$, middle of leaf; T, tip of leaf 
defense and stress-related proteins are also differentially expressed in LMMs. For example, probenazole-induced protein (PBZ1)/pathogen-related protein 10 (OsPR10, spot 26), which is a molecular marker in rice defense and stress response and can serve as a potential marker for cell death/PCD in rice (Kim et al., 2008), were highly induced in the psl mutant (Fig. 7). In addition, other defense/stress-related proteins such as thaumatin-like protein/OsPR5 (spot 27) were also remarkedly induced in the psl mutant, as observed in lesion mimic mutant spl1(Kim et al., 2008) and blm (Jung et al., 2006) .

Recent studies reveal that Glyceraldehyde-3-phosphate dehydrogenase (GAPDH) also mediates cell death by its nuclear translocation under oxidative stress in mice (Nakajima et al., 2009). Increased level of GAPDH protein was also observed in lesion mimic mutants (lmms) spl1, spl5 and $c d r 2$ (Chen et al., 2013b), suggesting its function in cell death and defense responses in rice. Besides metabolic function, 6-phosphogluconate dehydrogenase (Os6PGdh) plays a role in abiotic stresses in rice (Hou et al., 2007). Two enzymes of glycolysis, GAPDH and Os6PGDH, were up-regulated in psl mutant (Table 1 ), supporting the notion that the key enzyme of glycolysis metabolism may be involved in cell death and defense response in rice.

In differently expressed proteins, four enzymes including Methylenetetrahydrofolate reductase (MTHFR; up), aspartate aminotransferase (AST; up) and S-adenosylL-methionine (SAM) synthetase (SAMS1 and SAMS2; up) are associated with SAM metabolism (Table 1). MTHFR reduces 5,10-methylenetetrahydrofolate to 5-methyltetrahydrofolate, which is used to convert

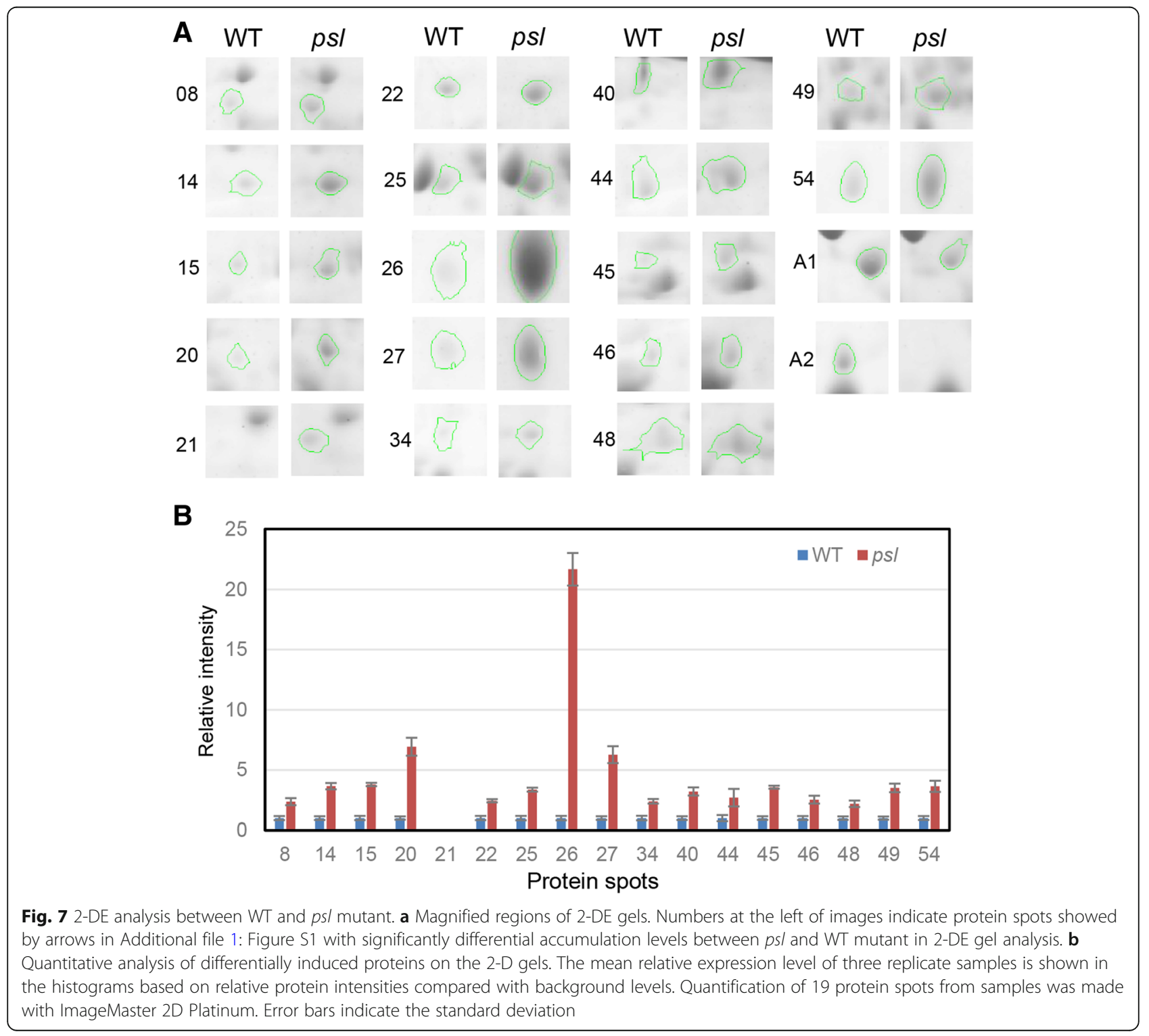


Table 1 Identification of proteins differentially expressed between WT and ps/ mutant

\begin{tabular}{|c|c|c|c|c|c|c|c|c|}
\hline Function type & Spot ID & Homologous protein & Score & $\begin{array}{l}\text { Coverage } \\
(\%)\end{array}$ & $\mathrm{pl}$ & $\begin{array}{l}\mathrm{MM} \\
(\mathrm{kDa})\end{array}$ & $\begin{array}{l}\text { Chang } \\
\text { fold }\end{array}$ & ID \\
\hline Photosynthesis & A01 & Rubisco activase alpha form (Rubisco-A) & 394 & 50 & 5.36 & 38.69 & -2.57 & LOC_Os11g47970 \\
\hline ROS metabolism & $\mathrm{A} 02$ & glutathione S-transferase OsGSTF3 & 143 & 38 & 5.81 & 25.51 & $\ll$ & LOC_Os03g04260 \\
\hline ROS metabolism & B25 & glutathione S-transferase & 315 & 35 & 5.50 & 25.34 & 3.36 & LOC_Os09g29200 \\
\hline ROS metabolism & B44 & GDP-d-mannose 3",5"-epimerase (GME) & 262 & 35 & 5.75 & 43.15 & 2.70 & LOC_Os10g28200 \\
\hline ROS metabolism & B45 & Monodehydroascorbate reductase (MDAR) & 253 & 31 & 5.30 & 46.77 & 3.56 & LOC_Os08g44340 \\
\hline Amino-acid metabolism & B08 & Methylenetetrahydrofolate reductase (MTHFR) & 260 & 32 & 5.75 & 64.66 & 2.36 & LOC_Os03g60090 \\
\hline Amino-acid metabolism & B14 & S-adenosylmethionine synthase (SAMS1) & 292 & 34 & 5.83 & 43.00 & 3.65 & LOC_Os05g04510 \\
\hline Amino-acid metabolism & B15 & S-adenosylmethionine synthase (SAMS2) & 355 & 35 & 5.68 & 43.33 & 3.79 & LOC_Os01g22010 \\
\hline Amino-acid metabolism/ & B46 & Aspartate aminotransferase (AST) & 411 & 46 & 5.90 & 46.02 & 2.53 & LOC_Os02g55420 \\
\hline GA-related & B20 & gibberellin receptor GID1L2 & 360 & 49 & 5.26 & 36.24 & 6.93 & LOC_Os07g06830 \\
\hline $\mathrm{Ca}^{2+}$ signal & B21 & $\begin{array}{l}\text { Calcium-dependent lipid-binding (CaLB) } \\
\text { protein }\end{array}$ & 308 & 46 & 5.97 & 30.51 & $\gg$ & LOC_Os09g39770 \\
\hline $\mathrm{Ca}^{2+}$ signal & B22 & $\begin{array}{l}\text { Calcium-dependent lipid-binding (CaLB) } \\
\text { protein }\end{array}$ & 309 & 42 & 4.77 & 30.38 & 2.44 & LOC_Os08g44850 \\
\hline Defense-related & B26 & OsPR10a/PBZ1 & 202 & 46 & 4.88 & 16.91 & 21.68 & LOC_Os12g36880 \\
\hline Defense-related & B27 & thaumatin-like protein (OsPR5) & 190 & 22 & 5.07 & 18.55 & 6.27 & LOC_Os12g43380 \\
\hline Stress-related & B34 & PDI-like protein/nucleoredoxin & 231 & 28 & 4.95 & 64.05 & 2.39 & LOC_Os03g29190 \\
\hline Stress-related & B54 & $\begin{array}{l}\text { Translationally-controlled tumor protein } \\
\text { (TCTP) }\end{array}$ & 283 & 55 & 4.51 & 18.99 & 3.64 & LOC_Os11g43900 \\
\hline pentose phosphate pathway & B40 & $\begin{array}{l}\text { 6-phosphogluconate dehydrogenase } \\
\text { (Os6PGDH) }\end{array}$ & 215 & 35 & 5.85 & 52.97 & 3.21 & LOC_Os06g02144 \\
\hline Glycolysis & B49 & $\begin{array}{l}\text { Glyceraldehyde-3-phosphate dehydrogenase } \\
\text { (GAPDH) }\end{array}$ & 159 & 19 & 6.22 & 47.54 & 3.51 & LOC_Os03g03720 \\
\hline Chloroplast protein & B48 & $\begin{array}{l}\text { Import intermediate associated protein } \\
\text { IAP100 }\end{array}$ & 94 & 21 & 6.57 & 40.45 & 2.19 & LOC_Os10g35030 \\
\hline
\end{tabular}

$\ll$, much less than; $»$, much greater than

homocysteine to methionine (Goyette et al., 1994). Aspartate is converted to homocysteine by a series of enzymes including AST and is also linked to methionine metabolism (Hesse and Hoefgen, 2003). SAM synthase (SAMS) plays the role of catalyzing the synthesis of SAM from methionine and ATP (Chu et al., 2013). Because SAM acts as the precursor in the biosynthesis of the plant hormone ethylene (Roje, 2006), the findings imply that the mutation of OSPSL might alter SAM metabolism, in turn affecting ethylene biosynthesis.

The induction of many defense-related proteins, such as PBZ1/OsPR10, thaumatin-like protein/OsPR5 and translationally controlled tumor protein (TCTP), was also found in the leaves of the psl mutant. Some proteins are not only stress-related/PR proteins, but also involved in ethylene response. For example, in tobacco (Nicotiana tabacum), NtTCTP protein accumulation is induced by ethylene treatment and interacts with a subfamily II ethylene receptor Histidine Kinase1 (NTHK1) to regulate plant growth and response to ethylene (Tao et al., 2015). In rice, TCTP is a single-copy gene that has diverse roles in response to various stresses (Wang et al., 2015). Thus, the induction of TCTP in psl mutant might be due to increased ethylene signaling.

To avoid the oxidative damage to other cells in plants, the ROS, such as superoxide anion $\left(\mathrm{O}^{-}\right)$and $\mathrm{H}_{2} \mathrm{O}_{2}$, must be scavenged by the antioxidant enzymes SOD, CAT, APX, or GST etc. According to our results, $\mathrm{O}_{2}^{-}$and $\mathrm{H}_{2} \mathrm{O}_{2}$ are over-accumulated in leaves of psl mutant (Fig. 2). Therefore, up-regulation of antioxidant enzymes such as glutathione $S$-transferase might be a natural cellular response for scavenging excess ROS in psl mutant.

Increasing evidences suggest the function of the multifaceted regulator of GA signaling in plant stress response (De Vleesschauwer et al., 2016). The upregulation of GID1L was also found during defense response to pathogen attack in plants (Zhang et al., 2015; Zhang et al., 2018). The induction of gibberellin receptor GID1L2 and calcium-dependent lipid-binding (CaLB) proteins were also identified in the psl mutant, supporting the function of GA signaling in plant stress and defense response. 
The psl mutant contain higher levels of ethylene

As SAM synthesis is an early step in ethylene production in plants (Roje, 2006), it is possible that higher SAMS protein contents in psl mutants contributed to the ethylene synthesis. To test this possibility, we performed an ethylene assay. As expected, ethylene contents were higher in psl mutants than in WT plants (Fig. 8a). In addition, expression analysis showed that the transcript levels of ethylene-synthesis and responsive genes were increased in the psl mutant (Fig. 8b), consistent with the increased ethylene content. To ascertain whether the accumulation of ethylene was associated with the premature senescence phenotype of the psl mutant, the psl mutant and wild-type plants were treat with aminoethoxyvinylglycine (AVG), an ethylene biosynthesis inhibitor (Wang et al., 2002). Leaf senescence in psl mutants was relieved by the ethylene biosynthesis blocker (Fig. 8c). These results suggest that the accelerated senescence of psl plants may be associated with activation of the ethylene associated pathway.

\section{Discussion}

In this study, we reported the identification and characterization of an early leaf senescence mutant ( $p s l)$. The OsPSL gene was determined by a map-based cloning method. Its deduced amino acid sequence displays a high similarity to acetylglucosaminyl transferases family involved in protein O-glycosylation modification. During preparing for this article, Li et al. (Li et al., 2018) published premature leaf senescence mutant (ospls3). There are similarities between psl and ospls3 mutants in many respects, including the increased level of ethylene. Therefore, it is not surprising that psl is an allele of ospls3. ospls3 contains a 22-bp deletion, resulting in severe phenotypes, while the phenotypes are less severe in psl mutant, which have one amino acid deletion in conserved domain. Although several studies have uncovered functions for O-glycosylation in many key cellular processes (Zentella et al., 2016; Xu et al., 2017; Zentella et al., 2017), very few have been functionally related to senescence in plants. Taken with the findings by Li et al. (Li et al., 2018), it has been suggested that protein $\mathrm{O}$-glycosylation modification might plays an important role in leaf senescence.

PCD is a fundamental process in plant development, environmental stresses and pathogens attacks. DNA fragmentation is a hallmark of PCD (Bröker et al., 2005). PBZ1 has been proposed as PCD marker protein in rice (Kim et al., 2008), which induced cell death possibly via its RNAse activity (Kim et al., 2011). In this study, we observed that the psl mutants display HR-like lesion in the absence of pathogens attacks (Fig. 1), ROS accumulation (Fig. 2) and clear DNA fragmentation (Fig. 3). Proteomic data showed that defense- or PCD-related-protein, including probenazole-induced protein (PBZ1), were significantly up-regulated in the psl mutant compared with WT. These results indicate that a mutation of OSPSL leads to $\mathrm{PCD}$ in rice.
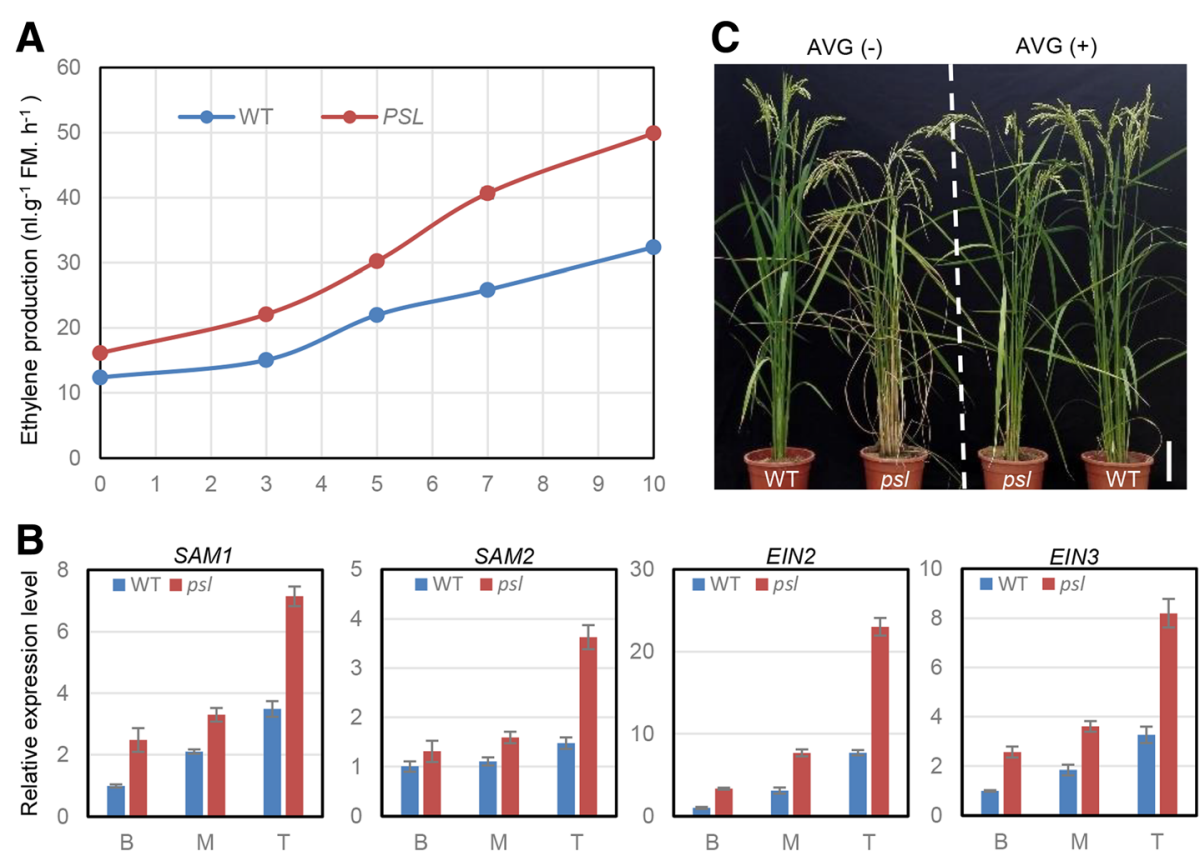

Fig. 8 Ethylene is associated with leaf senescence in psl. a Ethylene content in WT and psl. b Expression of ethylene-synthesis and responsive genes were increased in the ps/ mutant. 25sRNA was used as the internal control. c Application of exogenous AVG, an inhibitor of ethylene biosynthesis, retarded leaf senescence in ps/ mutant 
Increasing evidences indicate that SAM synthetase (SAMS) is a broad-spectrum signaling molecule that regulates plant development and defense responses to various stresses through methylation reactions or ethylene biosynthesis pathway (Zhao et al., 2017). S-adenosylmethionine (SAM) is synthesized by SAM synthetase from methionine and ATP, and serves as a methyl group donor in secondary metabolism and a precursor of plant hormones ethylene. As methyl group, SAM is involved in methylation modification of DNA, RNA, proteins and lipids, and the synthesis of lignin monors, coniferyl and sinapyl alcohols, which require SAM-dependent methyltransferase (Roje, 2006). SAM metabolism is also required for ethylene production in plants. In this case, SAMS acts as a key component of the ethylene synthesis pathway and its activity is transcriptionally or post-translationally regulated in response to phytohormones, biotic and abiotic stress (Chen et al., 2013b; Mao et al., 2015; Jin et al., 2017). For example, rice dwarf virus (RDV) infection can enhance enzymatic activity of SAMS1 without upregulating its mRNA through an interaction of RDV-encoded protein Pns11 with OsSAMS1 and increase the production of ethylene (Zhao et al., 2017). Furthermore, it has been demonstrated that SAMS overexpression can confer plant hormone ethylene overproduction (Jin et al., 2017; Zhao et al., 2017). Therefore, the level of SAMS in plant cells is tightly associated with hormonal control of plant cell metabolism and development to adapt environmental and developmental signals. Consistent with the previous findings above mentioned, the expression of the SAMSs were substantially up-regulated in psl mutant (Fig. 8) and its protein levels were 6-fold higher than WT (Fig. 7), leading to higher ethylene level, which may contribute to the early senescence of psl mutant.

Protein O-glycosylation is a highly dynamic posttranslational modification and plays an important role in regulating signal transduction pathways (Fülöp et al., 2008). Arabidopsis has two putative O-linked Nacetylglucosamine (O-GlcNAc) transferase (OGT): SPINDLY (SPY) and SECRET AGENT (SEC). Della, a master growth repressors in plants by inhibiting phytohormone gibberellin (GA) signaling, have been shown to be subject to O-GlcNAc modification by O-linked $\mathrm{N}$-acetylglucosamine (O-GlcNAc) transferase (OGT) SECRET AGENT (SEC) in Arabidopsis (Zentella et al., 2016). Recently, Zentella, et al. reported that SPY is a protein O-fucosyltransferase and SPY and SEC competed with each other in modifying Della protein RGA (Zentella et al., 2017). Rice has three putative OGTs genes: SPY, SEC1 and SEC2 (Shimada et al., 2006). Genetic evidence indicates that OGTs is as important in rice as in Arabidopsis (Shimada et al., 2006). Interestingly, the expression levels of rice OGTs were severely down-regulated in psl mutants compare to WT, suggesting the possible alteration of O-glycosylation modification, including rice DELLA protein SLR1. Thus, this might have an effect on GA signaling pathway. In support of this, the expression of OsGID1, encoding gibberellin receptor protein, was significantly suppressed in psl mutant. In addition, our data shows that defense-related proteins such as PBZ1/OsPR10 are over accumulated in psl mutant (Fig. 7), as observed in a rice GA-insensitive dwarf mutant gid1(Tanaka et al., 2005). These results support the putative role of OsPSL in $\mathrm{O}$-glycosylation protein modification. It is therefore possible that the early leaf senescence of $p s l$ mutant may be associated with suppression of GA pathway and activation of ethylene-associated pathway, due to impaired O-glycosylation protein modification in leaf tissue of psl mutant. Our study reveals the potential role of OsPSL in regulating leaf senescence. However, the biochemical function of OsPSL remains unsolved. Future studies should uncover the biochemical function of OsPSL and identify its target proteins.

\section{Conclusions}

In the present study, we propose that OsPSL plays an important role in regulating PCD and leaf senescence in rice. In addition, our results suggest the early leaf senescence of psl mutant may be associated with activation of ethylene-associated pathway, due to impaired protein glycosylation.

\section{Additional files}

Additional file 1: Figure S1. Comparison of nucleotide sequences between WT and ps/ mutant. Figure S2. Three-dimensional structure prediction of OsPSL protein. Figure S3. Representative 2-D gel protein profiles of leaves from WT and ps/ mutant. Table S1. List of primers used in this study. Table S2. Comparisons of agronomic traits between WT and ps/ mutant. (PDF 477 kb)

\section{Abbreviations}

2-DGE: Two-dimensional gel electrophoresis; 6PGDH: 6-phosphogluconate dehydrogenase; AVG: Aminoethoxyvinylglycine; C2GnT: Core 2/l branching beta-1,6-N-acetylglucosaminyl transferases; DAB: 3,3'-diaminobenzidine; GalNAc: N-acetylgalactosamine; GAPDH: Glyceraldehyde-3-phosphate dehydrogenase; Imm: Lesion mimic mutants; NBT: Nitro blue tetrazolium; OGTs: O-linked N-acetylglucosamine (O-GlcNAc) transferases; PBZ1: Probenazole-induced protein; PCD: Programmed cell death; ROS: Reactive oxygen species; SAMS: S-adenosyl methionine (SAM) synthetase

\section{Acknowledgements}

We thank Dr. Haitao Zhu (South China Agricultural University, China) for assistance with the map-based cloning of the OsPSL gene.

\section{Funding}

This work was supported by the National Natural Science Foundation of China (grant nos. 31671594 and 30900884 to XQ. Zhang); by Natural Science Foundation of Guangdong Province, China (grant nos. 2014 A030313457 and 2015A020209118 to XQ. Zhang). 


\section{Availability of data and materials}

The datasets supporting the conclusions of this article are included within the article and its additional files.

\section{Authors' contributions}

S.K. and S.L. performed experiments and conducted fieldwork. X.L. worked on the transgenic lines. X.M.X. designed the experiments and analyzed the data; T.F.H. supervised and complemented the writing; X.Q.Z. conceived the project and wrote the article with contributions of all the authors. All authors read and approved the final manuscript.

\section{Ethics approval and consent to participate}

Not applicable.

\section{Consent for publication}

Not applicable.

\section{Competing interests}

The authors declare that they have no competing interests.

\section{Publisher's Note}

Springer Nature remains neutral with regard to jurisdictional claims in published maps and institutional affiliations.

\section{Author details}

${ }^{1}$ Guangdong Engineering Research Center of Grassland Science, College of Forestry and Landscape Architecture, South China Agricultural University, Guangzhou 510642, China. ${ }^{2}$ Plants for Human Health Institute, North Carolina State University, North Carolina Research Campus, Kannapolis, NC 28081, USA. ${ }^{3}$ Department of Plant and Microbial Biology, North Carolina State University, Raleigh, NC 27695, USA

Received: 17 September 2018 Accepted: 1 February 2019

Published online: 13 February 2019

\section{References}

Bröker LE, Kruyt FAE, Giaccone G (2005) Cell death independent of caspases: a review. Clin Cancer Res 11:3155

Chen X, Fu S, Zhang P, Gu Z, Liu J, Qian Q, Ma B (2013a) Proteomic analysis of a disease-resistance-enhanced lesion mimic mutant spotted leaf 5 in rice. Rice 6:1

Chen Y, Xu Y, Luo W, Li W, Chen N, Zhang D, Chong K (2013b) The F-box protein OsFBK12 targets OsSAMS1 for degradation and affects pleiotropic phenotypes, including leaf senescence, in rice. Plant Physiol 163:1673-1685

Chu J, Qian J, Zhuang Y, Zhang S, Li Y (2013) Progress in the research of Sadenosyl-I-methionine production. Appl Microbiol Biotechnol 97:41-49

Dangl JL, Dietrich RA, Richberg MH (1996) Death don't have no mercy: cell death programs in plant-microbe interactions. Plant Cell 8:1793-1807

Fülöp N, Feng W, Xing D, He K, Nőt LG, Brocks CA, Marchase RB, Miller AP, Chatham JC (2008) Aging leads to increased levels of protein O-linked Nacetylglucosamine in heart, aorta, brain and skeletal muscle in BrownNorway rats. Biogerontology 9:139

Gomord V, Fitchette A, Menu-Bouaouiche L, Saint-Jore-Dupas C, Plasson C, Michaud D, Faye L (2010) Plant-specific glycosylation patterns in the context of therapeutic protein production. Plant Biotechnol J 8:564-587

Goyette P, Sumner JS, Milos R, Duncan AMV, Rosenblatt DS, Matthews RG, Rozen R (1994) Human methylenetetrahydrofolate reductase: isolation of cDNA, mapping and mutation identification. Nat Genet 7:195-200

Hesse H, Hoefgen R (2003) Molecular aspects of methionine biosynthesis. Trends Plant Sci 8:259-262

Hiei Y, Ohta S, Komari T, Kumashiro T (1994) Efficient transformation of rice (Oryza sativa $\mathrm{L}$.) mediated by agrobacterium and sequence analysis of the boundaries of the T-DNA. Plant J 6:271-282

Hou F, Huang J, Yu S, Zhang H (2007) The 6-phosphogluconate dehydrogenase genes are responsive to abiotic stresses in rice. J Integr Plant Biol 49:655-663

Jibran R, Hunter AD, Dijkwel PP (2013) Hormonal regulation of leaf senescence through integration of developmental and stress signals. Plant Mol Biol 82: $547-561$

Jin Y, Ye N, Zhu F, Li H, Wang J, Jiang L, Zhang J (2017) Calcium-dependent protein kinase CPK28 targets the methionine adenosyltransferases for degradation by the 265 proteasome and affects ethylene biosynthesis and lignin deposition in Arabidopsis. Plant J 90:304-318

Jung Y, Rakwal R, Agrawal GK, Shibato J, Kim J, Lee MO, Choi P, Jung S, Kim SH, Koh $\mathrm{H}$, Yonekura M, Iwahashi H, Jwa N (2006) Differential expression of defense/stress-related marker proteins in leaves of a unique rice blast lesion mimic mutant (b/m). J Proteome Res 5:2586-2598

Kim SG, Kim ST, Wang Y, Yu S, Choi IS, Kim YC, Kim WT, Agrawal GK, Rakwal R, Kang KY (2011) The RNase activity of rice probenazole-induced protein1 (PBZ1) plays a key role in cell death in plants. Mol Cells 31:25-31

Kim ST, Kim SG, Kang YH, Wang Y, Kim J, Yi N, Kim J, Rakwal R, Koh H, Kang KY (2008) Proteomics analysis of rice lesion mimic mutant (sp/1) reveals tightly localized probenazole-induced protein (PBZ1) in cells undergoing programmed cell death. J Proteome Res 7:1750-1760

Kojima Y, Yoneyama T, Hatakeyama S, Mikami J, Sato T, Mori K, Hashimoto Y, Koie T, Ohyama C, Fukuda M, Tobisawa Y (2015) Detection of core2 B-1,6-nacetylglucosaminyltransferase in post-digital rectal examination urine is a reliable indicator for extracapsular extension of prostate cancer. PLoS One 10: e138520

Li K, Chen Y, Luo Y, Huang F, Zhao C, Cheng F, Xiang X, Pan G (2018) A 22-bp deletion in OsPLS3 gene encoding a DUF266-containing protein is implicated in rice leaf senescence. Plant Mol Biol 98:19-32

Li Q, Wan J (2005) SSRHunter: development of a local searching software for SSR sites. Hereditas 27:808-810

Mao D, Yu F, Li J, Van de Poel B, Tan D, Li J, Liu Y, Li X, Dong M, Chen L, Li D, Luan S (2015) FERONIA receptor kinase interacts with S-adenosylmethionine synthetase and suppresses S-adenosylmethionine production and ethylene biosynthesis in Arabidopsis. Plant Cell Environ 38:2566-2574

Michelmore RW, Paran I, Kesseli RV (1991) Identification of markers linked to disease-resistance genes by bulked segregant analysis: a rapid method to detect markers in specific genomic regions by using segregating populations. Proc Natl Acad Sci U S A 88:9828-9832

Moran AP, Gupta A, Joshi L (2011) Sweet-talk: role of host glycosylation in bacterial pathogenesis of the gastrointestinal tract. Gut 60:1412-1425

Nakajima H, Amano W, Kubo T, Fukuhara A, Ihara H, Azuma Y, Tajima H, Inui T, Sawa A, Takeuchi T (2009) Glyceraldehyde-3-phosphate dehydrogenase aggregate formation participates in oxidative stress-induced cell death. J Biol Chem 284:34331-34341

Olszewski NE, West CM, Sassi SO, Hartweck LM (2010) O-GlcNAc protein modification in plants: evolution and function. Biochimica Biophysica Acta (BBA) 1800:49-56

Qiao Y, Jiang W, Lee J, Park B, Choi M, Piao R, Woo M, Roh J, Han L, Paek N, Seo HS, Koh H (2009) SPL28 encodes a clathrin-associated adaptor protein complex 1, medium subunit $\mu 1$ (AP1M1) and is responsible for spotted leaf and early senescence in rice (Oryza sativa). New Phytol 185:258-274

Roje S (2006) S-Adenosyl-I-methionine: beyond the universal methyl group donor. Phytochemistry 67:1686-1698

Shen Y, Jiang H, Jin J, Zhang Z, Xi B, He Y, Wang G, Wang C, Qian L, Li X, Yu Q, Liu H, Chen D, Gao J, Huang H, Shi T, Yang Z (2004) Development of genome-wide DNA polymorphism database for map-based cloning of rice genes. Plant Physiol 135:1198-1205

Shimada A, Ueguchi-Tanaka M, Sakamoto T, Fujioka S, Takatsuto S, Yoshida S, Sazuka T, Ashikari M, Matsuoka M (2006) The rice SPINDLY gene functions as a negative regulator of gibberellin signaling by controlling the suppressive function of the DELLA protein, SLR1, and modulating brassinosteroid synthesis. Plant J 48:390-402

Tanaka N, Matsuoka M, Kitano H, Asano T, Kaku H, Komatsu S (2005) gid1, a gibberellin-insensitive dwarf mutant, shows altered regulation of probenazole-inducible protein (PBZ1) in response to cold stress and pathogen attack. Plant Cell Environ 29:619-631

Tao J, Cao Y, Chen H, Wei W, Li Q, Ma B, Zhang W, Chen S, Zhang J (2015) Tobacco translationally controlled tumor protein interacts with ethylene receptor tobacco histidine kinase 1 and enhances plant growth through promotion of cell proliferation. Plant Physiol 169:96-114

Thakur N, Sharma V, Kishore K (2016) Leaf senescence: an overview. Indian J Plant Physiol 21:225-238

Trobacher CP (2009) Ethylene and programmed cell death in plants. Botany 87: 757-769

De Vleesschauwer D, Seifi HS, Filipe O, Haeck A, Huu SN, Demeestere K, Höfte M (2016) The DELLA protein SLR1 integrates and amplifies salicylic acid- and jasmonic acid-dependent innate immunity in rice. Plant Physiol 170:1831-1847 
Wang KLC, Li H, Ecker JR (2002) Ethylene biosynthesis and signaling networks. Plant Cell 14:S131-S151

Wang ZQ, Li GZ, Gong QQ, Li GX, Zheng SJ (2015) OsTCTP, encoding a translationally controlled tumor protein, plays an important role in mercury tolerance in rice. BMC Plant Biol 15:123. https://doi.org/10.1186/ s12870-015-0500-y

Xing L, Liu Y, Xu S, Xiao J, Wang B, Deng H, Lu Z, Xu Y, Chong K (2018) Arabidopsis O-GICNAC transferase SEC activates histone methyltransferase ATX1 to regulate flowering. EMBO J pii e98115. https://doi.org/10.15252/ embj.201798115

Xu S, Chalkley RJ, Maynard JC, Wang W, Ni W, Jiang X, Shin K, Cheng L, Savage D, Hühmer AFR, Burlingame AL, Wang Z (2017) Proteomic analysis reveals OGlcNAc modification on proteins with key regulatory functions in Arabidopsis. Proc Natl Acad Sci U S A 114:E1536-E1543

Yang X, Gong P, Li K, Huang F, Cheng F, Pan G (2016) A single cytosine deletion in the OsPLS1 gene encoding vacuolar-type H+-ATPase subunit A1 leads to premature leaf senescence and seed dormancy in rice. J Exp Bot 67:2761-2776

Yang Y, Yoo CG, Guo H, Rottmann W, Winkeler KA, Collins CM, Gunter LE, Jawdy SS, Yang X, Guo H, Pu Y, Ragauskas AJ, Tuskan GA, Chen J (2017) Overexpression of a domain of unknown function 266-containing protein results in high cellulose content, reduced recalcitrance, and enhanced plant growth in the bioenergy crop Populus. Biotechnol Biofuels 10:74. https://doi. org/10.1186/s13068-017-0760-X

Ye J, Pan Q, Shang Y, Wei X, Peng Z, Chen W, Chen L, Wang R (2015) Core 2 mucin-type O-glycan inhibits EPEC or EHEC 0157:H7 invasion into HT-29 epithelial cells. Gut pathogens 7:31. https://doi.org/10.1186/s13099-015-0078-9

Zentella R, Hu J, Hsieh W, Matsumoto PA, Dawdy A, Barnhill B, Oldenhof H, Hartweck LM, Maitra S, Thomas SG, Cockrell S, Boyce M, Shabanowitz J, Hunt DF, Olszewski NE, Sun T (2016) O-GlcNAcylation of master growth repressor DELLA by SECRET AGENT modulates multiple signaling pathways in Arabidopsis. Genes Dev 30:164-176

Zentella R, Sui N, Barnhill B, Hsieh W, Hu J, Shabanowitz J, Boyce M, Olszewski NE, Zhou P, Hunt DF, Sun T (2017) The Arabidopsis O-fucosyltransferase SPINDLY activates nuclear growth repressor DELLA. Nat Chem Biol 13:479-485

Zhang F, Huang L, Zhang F, Ali J, Cruz CV, Zhuo D, Du Z, Li Z, Zhou Y (2015) Comparative transcriptome profiling of a rice line carrying Xa39 and its parents triggered by Xanthomonas oryzae pv. Oryzae provides novel insights into the broad-spectrum hypersensitive response. BMC Genomics 16:111. https://doi.org/10.1186/s12864-015-1329-3

Zhang M, Xu J, Liu G, Yao X, Ren R, Yang X (2018) Proteomic analysis of responsive root proteins of Fusarium oxysporum-infected watermelon seedlings. Plant Soil 422:169-181

Zhang X, Hou P, Zhu H, Li G, Liu X, Xie X (2013) Knockout of the VPS22 component of the ESCRT-II complex in rice (Oryza sativa L.) causes chalky endosperm and early seedling lethality. Mol Biol Rep 40:3475-3481

Zhao S, Hong W, Wu J, Wang Y, Ji S, Zhu S, Wei C, Zhang J, Li Y, Greenberg JT (2017) A viral protein promotes host SAMS1 activity and ethylene production for the benefit of virus infection. elife 6:e27529 pii: e27529. https:/doi.org/ 10.7554/eLife.27529

\section{Submit your manuscript to a SpringerOpen ${ }^{\circ}$ journal and benefit from:}

- Convenient online submission

- Rigorous peer review

- Open access: articles freely available online

- High visibility within the field

- Retaining the copyright to your article

Submit your next manuscript at $\boldsymbol{\nabla}$ springeropen.com 